\title{
Safety and effectiveness of switching to Abacavir/Lamivudine plus rilpivirine for maintenance therapy in virologically suppressed HIV-1 individuals in Singapore (SEALS)
}

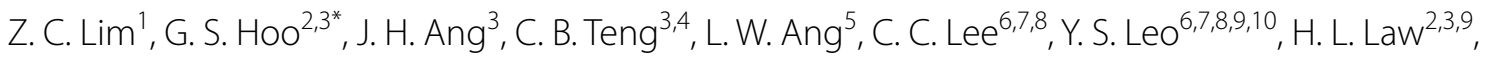
O. T. $\mathrm{Ng}^{6,7,9}$ and C. S. Wong ${ }^{6,7,8}$

\begin{abstract}
Background: The efficacy and tolerability of an antiretroviral regimen are important considerations for selection of HIV-1 infection maintenance therapy. Abacavir/lamivudine plus rilpivirine (ABC/3TC + RPV) has been shown in international studies to be effective and well-tolerated in virologically suppressed individuals. This study evaluated the effectiveness and safety of switching to ABC/3TC + RPV as maintenance therapy in virologically suppressed HIV-1 infected individuals in Singapore.

Methods: In this retrospective, single-centre study, we included individuals who were prescribed ABC/3TC + RPV, had HIV-1 viral load $(\mathrm{VL})<50$ copies/ml immediately pre-switch, and had no documented history of resistance mutations or virologic failure to any of the components. The follow-up period was $48 \pm 12$ weeks. The primary outcome was the proportion of individuals who maintained virologic suppression of $\mathrm{HIV}-1 \mathrm{VL}<50 \mathrm{copies} / \mathrm{ml}$ at the end of follow-up period based on on-treatment analysis. The secondary outcomes were the resistance profiles associated with virologic failure, changes in immunologic and metabolic parameters, and the safety profile of ABC/3TC + RPV.

Results: A total of 222 individuals were included in the study. The primary outcome was achieved in 197 individuals [88.8\%, 95\% confidence interval: 83.7-92.4\%]. There were 21 individuals (9.5\%) who discontinued treatment for nonvirologic reasons. The remaining 4 individuals experienced virologic failure, of whom, 3 of these individuals had developed emergent antiretroviral resistance and had HIV-1 VL $>500$ copies/ml at the end of the $48 \pm 12$ weeks follow-up period. The remaining individual experienced sustained low level viremia and subsequently achieved viral suppression without undergoing resistance testing. A total of 49 adverse events were observed in 31 out of 222 individuals (14.0\%), which led to 13 individuals discontinuing therapy. Neuropsychiatric adverse events were most commonly observed (53.1\%). A statistically significant increase in CD4 was observed $(p<0.01)$, with a median absolute change of 31 cells/uL (interquartile range: - 31.50 to 140.75). No significant changes in lipid profiles were detected.
\end{abstract}

*Correspondence: grace_sr_hoo@ttsh.com.sg

${ }^{2}$ Department of Pharmacy, National Centre of Infectious Diseases, Singapore, Singapore

Full list of author information is available at the end of the article

(c) The Author(s) 2021. Open Access This article is licensed under a Creative Commons Attribution 4.0 International License, which permits use, sharing, adaptation, distribution and reproduction in any medium or format, as long as you give appropriate credit to the original author(s) and the source, provide a link to the Creative Commons licence, and indicate if changes were made. The images or other third party material in this article are included in the article's Creative Commons licence, unless indicated otherwise in a credit line to the material. If material is not included in the article's Creative Commons licence and your intended use is not permitted by statutory regulation or exceeds the permitted use, you will need to obtain permission directly from the copyright holder. To view a copy of this licence, visit http://creativecommons.org/licenses/by/4.0/. The Creative Commons Public Domain Dedication waiver (http://creativeco mmons.org/publicdomain/zero/1.0/) applies to the data made available in this article, unless otherwise stated in a credit line to the data. 
Conclusion: $A B C / 3 T C+R P V$ is a safe and effective switch option for maintenance therapy in virologically suppressed HIV-1 individuals with in Singapore.

Keywords: Maintenance, Switch therapy, Virologically suppressed, Abacavir, Rilpivirine, HIV

\section{Background}

Modern combination antiretroviral therapy (ART) regimens have generally demonstrated potency and efficacy in achieving virologic suppression [1]. Owing to the chronic nature of HIV infection, maintenance therapy is required even after initial virologic suppression [1]. In addition to efficacy, the cost-effectiveness, convenience and long-term tolerability of the ART are important considerations in selecting a suitable maintenance therapy [1].

The current standard for HIV treatment is combination ART, which comprise of two nucleos(t)ide reverse transcriptase inhibitors (NRTI) as backbone, paired with a third agent from another class, including integrase strand transfer inhibitors (INSTI), non-nucleoside reverse transcriptase inhibitors (NNRTI), or protease inhibitors (PI) [1]. Tenofovir and emtricitabine (TDF/FTC) are recommended as a first-line NRTI backbone for their effectiveness, but the combination of abacavir and lamivudine (ABC/3TC) may be used as maintenance therapy for its cost-effectiveness and better safety profile [1-4]. Compared to tenofovir-based regimens, $\mathrm{ABC} / 3 \mathrm{TC}$ offer the advantage of avoiding potential renal and bone toxicity and is suitable for use in individuals with renal insufficiency and osteoporosis [1-4]. However, several studies suggest a possible increased cardiovascular risk for abacavir-based regimens, which remains a clinical concern $[5,6]$. In Singapore, the price of ABC/3TC is roughly half that of TDF and 3TC (as separate components), and one-fifth the cost of a TDF/FTC fixed dose combination tablet. Rilpivirine (RPV) is a second-generation NNRTI approved for use with NRTIs in treatment-naïve HIV-1 infected individuals [7-11]. Its use is recommended to be limited to individuals with pre-treatment CD4 counts exceeding 200 cells/uL and pre-treatment viral loads of less than 100,000 copies/ml [1]. RPV is also contraindicated in individuals with concomitant proton pump inhibitor use, and requires to be administered with a normal- to high-calorie meal for optimal absorption. Nonetheless, RPV has been shown to have fewer neuropsychiatric adverse effects (AEs) when compared with efavirenz, a more favourable metabolic profile compared with PI, and better cost-effectiveness due to its relatively lower cost [7-11]. In Singapore, the cost of RPV is $25 \%$ compared to that of a PI or INSTI. Due to the lower cost of $\mathrm{ABC} / 3 \mathrm{TC}$ and $\mathrm{RPV}$, they remain as enticing options for selected individuals who qualify for its use.
The SIMRIKI retrospective study has demonstrated the long-term effectiveness and safety of $\mathrm{ABC} / 3 \mathrm{TC}+\mathrm{RPV}$ as a switch therapy with a follow-up period of up to 48 weeks [12]. The results of the SIMRIKI study are corroborated by several similar Spanish studies [13-15]. In particular, these international studies seem to reinforce the long-term cardiovascular safety of $\mathrm{ABC} / 3 \mathrm{TC}+\mathrm{RPV}$ [12-15]. A local study has also shown the efficacy and safety of this regimen in treatment naïve HIV-1 infected adults, [16] but to our knowledge, there have not been any studies on the effectiveness and safety of $\mathrm{ABC} / 3 \mathrm{TC}+\mathrm{RPV}$ as a switch regimen in Singapore.

The aim of this study was to evaluate the effectiveness and safety of switching to $\mathrm{ABC} / 3 \mathrm{TC}+\mathrm{RPV}$ as maintenance therapy for virologically suppressed HIV-1 infected individuals in Singapore.

\section{Methods}

This study was a retrospective, single-centre evaluation conducted at National Centre for Infectious Diseases (NCID), which provides HIV care for the majority of HIV-infected individuals in Singapore. The study was conducted between June 2014 and September 2018. Approval from Domain Specific Review Board of the National Healthcare Group (Reference Number: 2012/00438-SRF0006) was obtained prior to study commencement.

The inclusion criteria were as follows: (i) documented HIV-1 infection, (ii) age $\geq 18$ years, (iii) use of combination of ABC/3TC (600/300 mg fixed dose combination once daily) plus RPV (25 mg once daily) as maintenance therapy between June 2014 and September 2018 inclusive, (iv) virologically suppressed (defined as having at least 1 reading of HIV-1 viral load $(\mathrm{VL})<50$ copies $/ \mathrm{ml}$ ) immediately before switching to $\mathrm{ABC} / 3 \mathrm{TC}+\mathrm{RPV}$, and (v) no documented history of resistance mutations or virologic failure to $A B C$, 3TC, FTC or RPV. Exclusion criteria were CD4 count $<200$ cells/uL and pregnancy. As adherence could not be determined for individuals who either obtained external supply of ART with no pharmacy dispensed records and/or with erratic clinic attendance, individuals with proportion of days covered (PDC) for adherence of $<95 \%$ were also excluded. PDC was calculated by the following formula: [Number of days with medication supply in study period / number of days in the study period] $\times 100$, capped at $100 \%$. PDC is a known, 
validated and stringent measure of adherence $[17,18]$. The cut-off for PDC was chosen to be $95 \%$ as it is a widely used standard for optimal ART [19].

Eligible individuals were identified from the NCID HIV Clinical Database, a standardised computerised database containing records of demographic information, HIV transmission route, and ART history. Data collected from electronic medical records included AEs attributed to ART, reasons for ART switch, and other laboratory readings which were not available on the Clinical Database. Data were anonymised upon extraction. Intervals for follow-up were determined by individual attending physicians per in-house clinical care guidelines.

The primary outcome measured was the proportion of individuals who maintained virologic suppression on $\mathrm{ABC} / 3 \mathrm{TC}+\mathrm{RPV}$ after $48 \pm 12$ weeks of follow-up and had no therapy discontinuation due to non-virologic reasons such as adverse drug reactions. Individuals were considered to have maintained virologic suppression if they had no virologic failure. Virologic failure was defined as: (i) 2 consecutive HIV-1 VL readings of $>50$ copies $/ \mathrm{ml}$, (ii) any HIV-1 VL $>50$ copies $/ \mathrm{ml}$ that resulted in discontinuation of $\mathrm{ABC} / 3 \mathrm{TC}+\mathrm{RPV}$, or (iii) any HIV-1 VL reading of $>500$ copies $/ \mathrm{ml}$. This definition for virological failure is similar to the SIMRIKI study, [12] but also included any HIV-1 VL reading of $>500$ copies $/ \mathrm{ml}$ to detect any potential emergent antiretroviral resistance. Individuals who had a oneoff HIV-1 VL reading between 51 copies $/ \mathrm{ml}$ and $<200$ copies/ml that was followed by a return to virologic suppression were considered virologic blips [1]. For all individuals, HIV-1 VL was measured at least twice throughout the follow-up period.

The secondary outcomes were the resistance profiles associated with virologic failure, changes in immunologic and metabolic parameters, and the $\mathrm{AE}$ profile of $\mathrm{ABC} / 3 \mathrm{TC}+\mathrm{RPV}$. For the immunologic and metabolic parameters, only individuals who had both baseline and follow-up values were analyzed for secondary outcomes.

The 95\% confidence intervals (CI) were calculated based on the Newcombe-Wilson hybrid score [20]. We checked whether the continuous variables were normally distributed using the Kolmogorov-Smirnov test (for $\mathrm{n} \geq 50$ ) and Shapiro-Wilk test (for $\mathrm{n}<50$ ). We then used the paired samples $t$-test to analyze variables with normal distribution, and the Wilcoxon Signed Rank test to analyze variables with non-normal distribution. All statistical tests were two-sided, and $\mathrm{p}$-values $<0.05$ were considered statistically significant. Statistical analysis was carried out using the IBM SPSS Statistics for Windows, version 24.0 (Armonk, NY: IBM Corp).

\section{Results}

We collected data from 346 individuals. A total of 222 individuals were included for analysis. The inclusion process of the study was detailed in Fig. 1. Baseline characteristics of the individuals included in the study were displayed in Table 1.

The median age was 47 years (interquartile range [IQR]:35-57). Majority of the individuals were men (92.3\%). The composition of pre-switch NRTI backbone (in combination with either 3TC or FTC) was as follows: TDF (60.8\%), ABC (27.0\%) zidovudine (10.3\%), and stavudine (1.9\%). The most common pre-switch third agents were efavirenz (42.3\%) among the NNRTI, atazanavir/ ritonavir (13.5\%) among the PI, and raltegravir (6.8\%) among the INSTI. Fifty-two (23.4\%) individuals already had RPV as their third agent prior to switch. The most common pre-switch combination was TDF $+3 \mathrm{TC}+\mathrm{RPV}$, which accounted for $45 / 222$ (20.3\%) of all pre-switch regimens. Intolerance $(52.7 \%)$, cost $(29.7 \%)$, and simplification of regimen $(23.4 \%)$ were the most common reasons cited for switching regimen. Thirty-one individuals (14.0\%) had no documented reason for switch.

The primary outcome was achieved in 197 out of 222 individuals [88.8\%, 95\% confidence interval (CI): 83.7-92.4\%]. For patients with an immediate pre-switch history of PI or INSTI-based treatment, 47 out of 56 individuals [83.9\%, 95\% CI: 72.2-91.3\%] achieved the primary outcome. For patients with an immediate preswitch history of NNRTI-based treatment, 150 out of 166 individuals [90.4\%, 95\% CI: 84.9-94.0\%] achieved the primary outcome.

Four individuals $(1.8 \%)$ had virologic failure (Additional file 1: Table S1), while 21 individuals $(9.5 \%)$ discontinued treatment for non-virologic reasons before $48 \pm 12$ weeks (Additional file 1: Table S2). Among those who achieved the primary outcome, 7 individuals had viral blips during the $48 \pm 12$ weeks follow-up period.

Of the 4 individuals who experienced virologic failure, 3 individuals had HIV-1 VL $>500$ copies $/ \mathrm{ml}$ at the end of the study period and developed emergent antiretroviral resistance. The first individual experienced virologic failure on the $52^{\text {th }}$ week of switching regimen. Resistance testing showed M184MIV, V108VI, E138EK, K238KN mutations. This individual reported no missed doses, but administered ART at irregular timings with inconsistent caloric intake. The second individual failed on the 45th week of $\mathrm{ABC} / 3 \mathrm{TC}+\mathrm{RPV}$ and had M184I, E138K, H221HY mutations. He estimated missing doses once a week, and having erratic meal consumption. The third individual experienced virologic failure within 17 weeks of switching regimen, with emerging resistance mutations consisting of L74LV, M184I, E138EG, Y181YCF, M230L. This individual claimed full adherence to his 


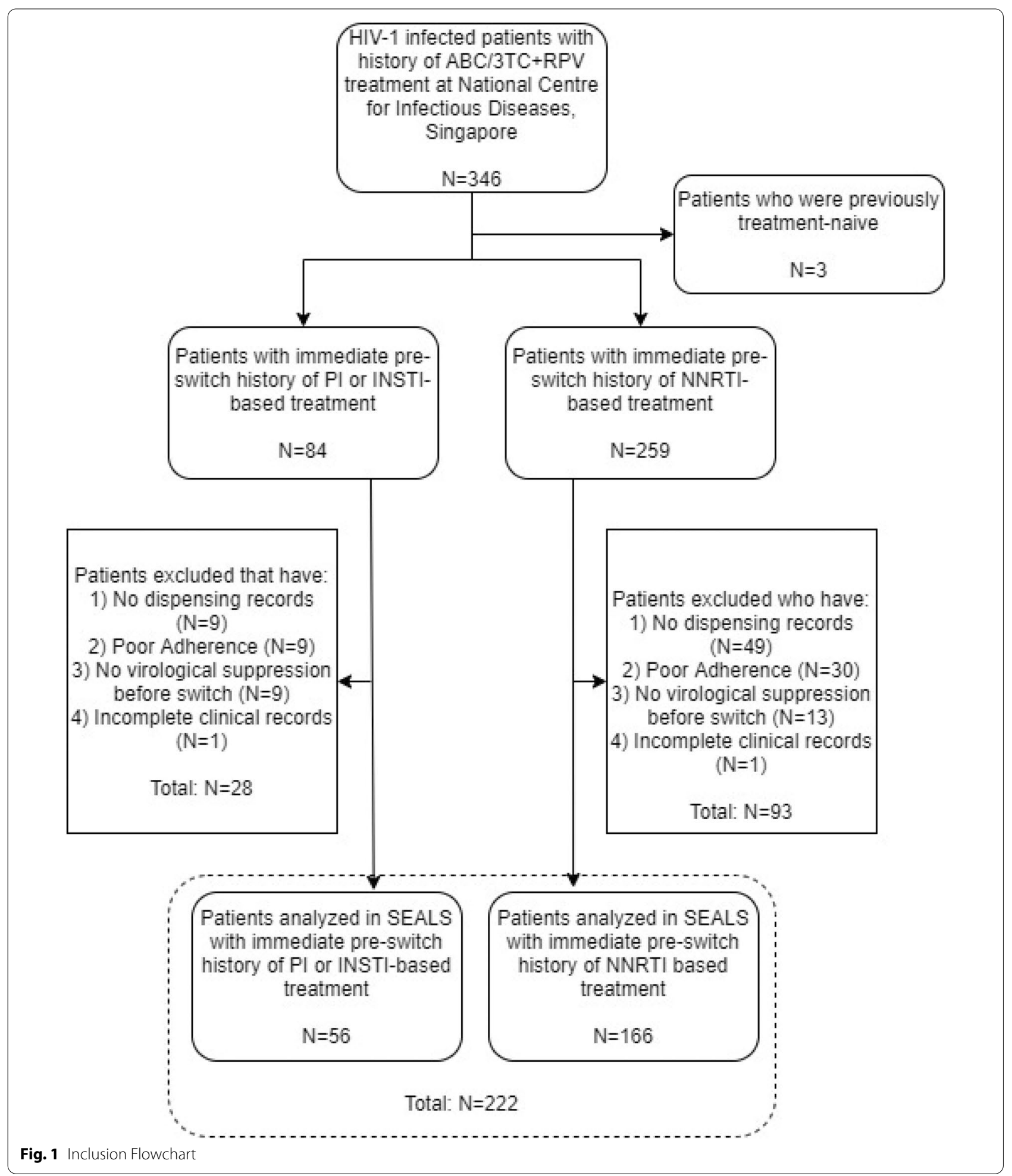

ART, including administration with meals. The last individual had 3 consecutive readings of low-level viremia (HIV-1 VL $>50$ copies/ml but $<200$ copies $/ \mathrm{ml}$ ). This individual later achieved virologic suppression without the need to change regimen after the study period.

Among the 21 individuals who discontinued treatment for non-virologic reasons, 13/21 (61.9\%) were 
Table 1 Baseline characteristics of study population

\begin{tabular}{|c|c|}
\hline \multicolumn{2}{|l|}{ Baseline Characteristic } \\
\hline Age (years), median (IQR) & $47(35-57)$ \\
\hline Male, n (\%) & $205(92.3)$ \\
\hline Duration of known HIV infection (years), median (IQR) & $5.6(3.6-8.4)$ \\
\hline \multicolumn{2}{|l|}{ Race, $n(\%)$} \\
\hline Chinese & $176(79.3)$ \\
\hline Malay & $32(14.4)$ \\
\hline Indian & $12(5.4)$ \\
\hline Others & $2(0.9)$ \\
\hline \multicolumn{2}{|l|}{ HIV Risk Group, n (\%) } \\
\hline Heterosexual Contact Only & $96(43.2)$ \\
\hline Homosexual Contact Only & $93(41.9)$ \\
\hline Bisexual Contact Only & $22(9.9)$ \\
\hline Intravenous Drug Use (IDU) Only & $3(1.4)$ \\
\hline Others (Heterosexual Contact + IDU, Homosexual Contact + IDU, Bisexual Contact + IDU) & $3(1.4)$ \\
\hline Unknown & $5(2.3)$ \\
\hline \multicolumn{2}{|l|}{ Previous ART, n (\%) } \\
\hline \multicolumn{2}{|l|}{ Backbone } \\
\hline Tenofovir/Lamivudine or Tenofovir/Emtricitabine & $135(60.8)$ \\
\hline Abacavir/Lamivudine & $60(27.0)$ \\
\hline Zidovudine/Lamivudine & $23(10.3)$ \\
\hline Stavudine/Lamivudine & $4(1.9)$ \\
\hline \multicolumn{2}{|l|}{ Third Agent } \\
\hline Efavirenz & $94(42.3)$ \\
\hline Rilpivirine & $52(23.4)$ \\
\hline Atazanavir/ritonavir & $30(13.5)$ \\
\hline Nevirapine & $20(9.0)$ \\
\hline Raltegravir & $15(6.8)$ \\
\hline Darunavir/ritonavir & $5(2.3)$ \\
\hline Dolutegravir & $4(1.8)$ \\
\hline Lopinavir/ritonavir & $2(0.9)$ \\
\hline \multicolumn{2}{|l|}{ Reasons for switching to ABC/3TC + RPV, $n$ (\%) } \\
\hline Intolerance & $117(52.7)$ \\
\hline Cost reduction & $66(29.7)$ \\
\hline Simplification of regimen & $52(23.4)$ \\
\hline Drug-drug interaction & $5(2.3)$ \\
\hline Others & $3(1.4)$ \\
\hline Unknown & $31(14.0)$ \\
\hline \multicolumn{2}{|l|}{ Comorbidities, n (\%) } \\
\hline Myocardial infarction & $4(1.8)$ \\
\hline Ischemic heart disease & $5(2.3)$ \\
\hline Other cardiovascular pathologies & $7(3.2)$ \\
\hline Hypertension & $39(17.6)$ \\
\hline Diabetes mellitus & $18(8.1)$ \\
\hline Dyslipidemia & $67(30.2)$ \\
\hline Kidney disease & $15(6.8)$ \\
\hline Hepatitis B & $7(3.2)$ \\
\hline Hepatitis C & $16(7.2)$ \\
\hline No. of individuals with 5 or more medications (polypharmacy), $n$ (\%) & $63(28.4)$ \\
\hline Current smokers, n (\%) & $41(18.5)$ \\
\hline
\end{tabular}

IQR interquartile range 
due to AEs attributed to ABC/3TC+RPV. The details of these AEs that led to discontinuation are reported in Additional file 1: Table S2. Of the remaining 8/21 (38.1\%) individuals that discontinued treatment for non-virologic reasons, half were to avoid drug-drug interactions with other concomitant medications, and one-quarter were due to personal financial issues. A total of 49 AEs were observed in 31 out of 222 individuals (14.0\%) during the follow-up period (Table 2). All the AEs resolved spontaneously or upon therapy discontinuation. The most common type of $\mathrm{AE}$ was neuro-psychiatric (e.g., forgetfulness, insomnia, mood changes, vivid dreams), comprising $26 / 49$ (53.1\%) of all AEs reported. Notably, there were no cardiovascular AEs reported for $A B C / 3 T C+R P V$ in the study period. A detailed breakdown of the AEs observed can be seen in Additional file 1: Table S3.

Data obtained on changes in the selected laboratory values over the study duration are summarized in Table 3. A statistically significant increase in CD4 was observed $(\mathrm{p}<0.01)$, with a median absolute change of 31 cells/uL (IQR: -31.50 to +140.75 ). There were no significant changes in fasting blood glucose and HbA1c after switching regimen, based on the small number of individuals analysed (11 individuals for fasting blood glucose and 8 individuals for HbA1c). There was a statistically significant change observed for eGFR $(\mathrm{p}<0.01)$, with a median absolute change of $-4.24 \mathrm{ml} /$ $\mathrm{min} / 1.73 \mathrm{~m}^{2}$ (IQR: -14.06 to +5.27 ), while no significant change was detected for $\mathrm{eCrCl}(\mathrm{p}=0.463)$, with a median absolute change of $-0.79 \mathrm{ml} / \mathrm{min}$ (IQR: -8.81 to +7.97). Additional details on the stratification of eGFR results at baseline and at the end of the follow up period are reported in Additional file 1: Table S4. No significant changes in lipid profiles were detected. A statistically significant decrease of $-6 \mathrm{U} / \mathrm{L}$ (IQR: -11 to 0) was seen for ALT.

Table 2 Summary of adverse events

Summary of adverse effects

Total number of adverse effects

Individuals with $\geq 1$ adverse effects

Individuals who discontinued therapy due to adverse effects

Types of adverse effects

Neuro-psychiatric (i.e. forgetfulness, insomnia, mood changes, vivid 26 dreams)

Digestive (i.e. abdominal pain, stomach-ache)

Dermatological (i.e. rash)

Others (e.g. fatigue, lipodystrophy, gynecomastia)

\section{Discussion}

Our results showed that a high proportion of individuals (88.8\%) who switched to $\mathrm{ABC} / 3 \mathrm{TC}+\mathrm{RPV}$ had maintained virologic suppression. The result is similar regardless of the type of pre-switch ART regimen. Virologic suppression was achieved in $83.9 \%$ of individuals with an immediate pre-switch history of PI or INSTI-based treatment, and $90.4 \%$ of individuals with an immediate pre-switch history of NNRTI-based treatment. In several studies in Spain, $86-88 \%$ of HIV-1 infected individuals maintained virologic suppression and avoided therapy discontinuation at 48 weeks or 12 months [13-15]. The SIMRIKI study also saw $91.2 \%$ of their study population achieving the same outcome at 48 weeks [12]. The findings of our study corroborated existing primary literature that individuals on treatment with $\mathrm{ABC} / 3 \mathrm{TC}+\mathrm{RPV}$ can achieve effective, sustained virologic suppression.

A local study found that $96 \%$ of treatment naïve HIV-1 infected individuals achieved virologic suppression at the end of 48 weeks of treatment with $\mathrm{ABC} / 3 \mathrm{TC}+\mathrm{RPV},[16]$ which was comparable to that of our study in which $98.0 \%$ (197/201) of individuals who completed follow-up without therapy discontinuation remained virologically suppressed. A subgroup analysis regarding the type of pre-switch ART regimen for these individuals yielded similar results. 97.9\% (47/48) of the individuals in the pre-switch PI or INSTI-based treatment group and $98.0 \%(150 / 153)$ of the individuals in the pre-switch NNRTI-based treatment group who completed follow-up without therapy discontinuation remained virologically suppressed. These results further echo the strongly positive existing literature on the effectiveness of $\mathrm{ABC} / 3 \mathrm{TC}+\mathrm{RPV}$, especially when there is a high level of compliance. In the event of virologic failure to $A B C / 3 T C+R P V$, individuals still have the option of switching to a salvage regimen which includes a PI or INSTI or both.

AEs were observed amongst 31/222 individuals $(14.0 \%)$ and resolved either spontaneously or upon discontinuation of the medication. These results were comparable to the favourable results of SIMRIKI study, [12] as well as the local study on treatment-naïve HIVinfected individuals, [16] which reported only $15.6 \%$ and $13.5 \%$ of individuals with observed AEs respectively. The AE profile seen in our study was also very similar to the local study which saw mostly neuropsychiatric AEs at a rate of $46.4 \%$ of all observed AEs compared to our study which saw $53.1 \%$ of observed AEs being neuropsychiatric [16]. In addition, none of the AEs observed were cardiovascular, in contrast to other studies that suggest the cardiovascular toxicity of $\mathrm{ABC}$-based regimens [5, 6]. These findings further 
Table 3 Laboratory values at baseline and at end of follow-up period

Median (IQR)

p-value

Laboratory parameter

Absolute CD4 Count $(n=38)$

Baseline (cells/uL)

323 (220 to 519)

Follow up (cells/uL)

397 (252 to 603)

Follow up Duration (Weeks)

49 (44 to 52 )

Change (cells/uL)

$31(-32$ to +141$)$

$<0.01^{\mathrm{b}}$

Glucose monitoring

Fasting blood glucose $(n=11)$

Baseline $(\mathrm{mmol} / \mathrm{L})$

5.1 (4.9 to 5.7$)$

Follow Up (mmol/L)

$5.2(4.7$ to 5.5$)$

Follow up Duration (Weeks)

Change (mmol/L)

50 (46 to 52 )

$0.3(-0.5$ to +0.4$)$

$0.654^{b}$

$\operatorname{HbA1c}(n=8)$

Baseline (\%)

5.75 (5.55 to 6.5$)$

Follow Up (\%)

Follow up Duration (Weeks)

Absolute Change (\%)

5.85 (5.5 to 6.78 )

50 (40 to 58 )

$0.05(-0.08$ to +0.2$)$

$0.288^{\mathrm{a}}$

Renal

$\operatorname{eGFR}(n=139)$

Baseline $\left(\mathrm{ml} / \mathrm{min} / 1.73 \mathrm{~m}^{2}\right)$

Follow Up (ml/min/1.73m²)

90 (78 to 104)

87 (76 to 99$)$

Follow up Duration (Weeks)

Change $\left(\mathrm{ml} / \mathrm{min} / 1.73 \mathrm{~m}^{2}\right)$

$\mathrm{eCrCl}(\mathrm{n}=139)$

Baseline $(\mathrm{ml} / \mathrm{min})$

Follow Up ( $\mathrm{ml} / \mathrm{min})$

Follow up Duration (Weeks)

Change ( $\mathrm{ml} / \mathrm{min})$

49 (40 to 54 )

-4 ( -14 to 5$)$

91 (76 to 106)

90 (76 to 106)

49 (40 to 54 )

$-1(-9$ to +8$)$

Lipids

TC $(n=38)$

Baseline $(\mathrm{mmol} / \mathrm{L})$

5.1 (4.6 to 6.0$)$

Follow Up (mmol/L)

5.2 (4.4 to 5.8 )

Follow up Duration (Weeks)

51 (45 to 54 )

HDL-C $(n=38)$

Change (mmol/L)

$0.1(-1.1$ to +0.8$)$

$0.778^{\mathrm{b}}$

Baseline ( $\mathrm{mmol} / \mathrm{L})$

1.0 (0.9 to 1.4$)$

Follow Up (mmol/L)

1.2 (0.9 to 1.3$)$

Follow up Duration (Weeks)

50 (45 to 54)

Change (mmol/L)

$0(-0.2$ to +0.2$)$

$0.762^{b}$

dC LDL-C $(n=38)$

Baseline $(\mathrm{mmol} / \mathrm{L})$

2.9 (2.6 to 3.6 )

Follow Up (mmol/L)

2.8 (2.4 to 3.5$)$

Follow up Duration (Weeks)

51 (45 to 54 )

Change $(\mathrm{mmol} / \mathrm{L})$

$-0.1(-0.5$ to +0.5$)$

$0.817^{b}$

$\operatorname{LDL}-\mathrm{C}(\mathrm{n}=35)$

Baseline $(\mathrm{mmol} / \mathrm{L})$

3.1 (2.6 to 3.7 )

Follow Up (mmol/L)

3.1 (2.7 to 3.7$)$

Follow up Duration (Weeks)

51 (45 to 54)

Change (mmol/L)

$0.1(-0.6$ to +0.7$)$

$0.972^{b}$

Liver

$\operatorname{ALT}(n=117)$

Baseline (U/L)

28 (21 to 44.5$)$

Follow Up (U/L)

22 (16 to 30 )

Follow up Duration (Weeks)

48 (41 to 52 )

Change (U/L)

$-6(-11$ to +0$)$

$<0.001^{\mathrm{a}}$

eGFR Estimated glomerular filtration rate, eCrCl Estimated creatinine clearance, $T C$ Total cholesterol, HDL-C High density lipoprotein cholesterol, $d C L D L-C$ Low density lipoprotein cholesterol estimated with the de Cordova equation. [21], LDL-C Low density lipoprotein cholesterol, ALT Alanine transaminase

${ }^{\text {a }}$ Wilcoxon signed rank test

${ }^{b}$ Paired samples t-test 
support the well-established safety and tolerability of $\mathrm{ABC} / 3 \mathrm{TC}+\mathrm{RPV}$.

Our cohort had a significant improvement of absolute CD4 count at the end of the $48 \pm 12$ weeks follow-up. The increase in the CD4 count can possibly be attributed to maintained virologic suppression, and was also seen in other switch studies with increases ranging from +48 to +262 cells/uL [13-15].

We observed a statistically significant decrease in eGFR but not in eCrCl. The median absolute changes in eGFR and $\mathrm{eCrCl}$ were deemed to be of little or no clinical relevance $[22,23]$, as a median change of $-4 \mathrm{ml} / \mathrm{min} / 1.73 \mathrm{~m}^{2}$ in eGFR or $-1 \mathrm{ml} / \mathrm{min}$ in $\mathrm{eCrCl}$ is unlikely to affect the staging of chronic kidney disease or acute kidney injury. We also observed a statistically significant decrease in ALT, but the magnitude of the change is clinically insignificant, [24] as the median change of $-6 \mathrm{U} / \mathrm{L}$ is insufficient to warrant any clinical action. Significant changes in eCrCl, eGFR and ALTs were rarely noted in other studies on $\mathrm{ABC} / 3 \mathrm{TC}+\mathrm{RPV}$, and it is likely that the regimen has no significant effect on these laboratory parameters [13-16].

While no statistically significant changes were detected for lipids, fasting blood glucose and HbA1c, the results warrant careful interpretation due to the small number of individuals with both baseline and follow-up values. Remarkably, the SIMRIKI study and the studies by Curran et al. and Palacios et al. all noted significant decreases in total cholesterol and LDL-C, as well as increases in HDL-C [12-14]. However, the local study by Ho et al. did not lend evidence to any significant effect of the regimen on lipids, [16] and there are no studies so far that we know of that have documented significant changes in fasting blood glucose and HbA1c.

Our study has several limitations. The absence of a control group prevented us from comparing the effectiveness and safety in individuals who would have continued with the prior regimen. We did not have access to baseline resistance testing information for our study population. As we excluded individuals who were $<95 \%$ adherent by PDC, our findings may not be generalizable to individuals with suboptimal adherence or who are compliant to ART despite irregular clinic attendance or who purchase external supplies of ART. Compliance to these medications will remain a key clinical prerequisite to therapy success. In practice, it will be crucial to take into account the relatively low genetic barrier to resistance and the ability of the individual to adhere to the caloric requirements of RPV when selecting this regimen. The frequency of adverse events may also have been underreported, as only adverse events that were reported and explicitly attributed to the regimen in clinical documentation were included in the study.
In conclusion, this study shows that $\mathrm{ABC} / 3 \mathrm{TC}+\mathrm{RPV}$ is an effective and safe switch option for maintenance therapy in virologically suppressed HIV-1 individuals in Singapore.

\section{Supplementary Information}

The online version contains supplementary material available at https://doi. org/10.1186/s12981-021-00402-7.

Additional file 1: Table S1. Details of 4 individuals who failed the primary outcome for virological reasons. Table S2. Details of 21 individuals who failed the primary outcome for non-virological reasons. Table S3. Breakdown of All AEs. Table S4. Changes in eGFR stratificationA from baseline to end of follow up period $(n=139)$

\section{Acknowledgements}

We thank everyone in the NCID Clinical HIV Programme who made this possible.

\section{Authors' contributions}

LZC and AJH collected the data. LZC performed the analysis. LZC and HGS wrote the manuscript. All authors read and approved the final manuscript.

Funding

None to declare.

\section{Availability of data and materials}

The dataset generated and/or analysed during the current study are not publicly available due to the Personal Data Protection Act in Singapore and the sensitivity of the diagnosis, but reversibly anonymised dataset is available from the corresponding author on reasonable request.

\section{Declarations}

\section{Ethics approval and consent to participate}

Ethics approval for use of the clinical data was obtained from the Singapore National Healthcare Group Domain Specific Review Board (Reference Number: 2012/00438-SRF0006).

\section{Consent for publication.}

Not applicable.

\section{Competing interests}

The authors declare that they have no competing interests.

\section{Author details}

${ }^{1}$ Department of Pharmacy, Ng Teng Fong General Hospital, Singapore,

Singapore. ${ }^{2}$ Department of Pharmacy, National Centre of Infectious Diseases, Singapore, Singapore. ${ }^{3}$ Department of Pharmacy, Tan Tock Seng Hospital, Singapore, Singapore. ${ }^{4}$ Department of Pharmacy, National University of Singapore, Singapore, Singapore. ${ }^{5}$ National Public Health and Epidemiology Unit, National Centre for Infectious Diseases, Singapore, Singapore. ${ }^{6}$ National Centre for Infectious Diseases, Singapore, Singapore. ${ }^{7}$ Department of Infectious Diseases, Tan Tock Seng Hospital, Singapore, Singapore. ${ }^{8}$ Yong Loo Lin School of Medicine, National University of Singapore, Singapore, Singapore. ${ }^{9}$ Lee Kong Chian School of Medicine, Nanyang Technological University, Singapore, Singapore. ${ }^{10}$ Saw Swee Hock School of Public Health, National University of Singapore, Singapore, Singapore.

Received: 26 October 2020 Accepted: 7 October 2021 Published online: 01 November 2021

References

1. Panel on Antiretroviral Guidelines for Adults and Adolescents. Guidelines for the use of antiretroviral agents in adults and adolescents with HIV. 
Department of Health and Human Services. http://www.aidsinfo.nih.gov/ ContentFiles/AdultandAdolescentGL.pdf. Accessed 21 May 2020

2. Swartz J, Vandekerckhove L, Ammerloon $\mathrm{H}$, et al. Efficacy of tenofovir and efavirenz in combination with lamivudine or emtricitabine in antiretroviral-naive patients in Europe. J Antimicrob Chemother. 2015;70(6):1850-7. https://doi.org/10.1093/jac/dkv033.

3. Colombo G. Cost-effectiveness analysis of initial HIV treatment under Italian guidelines. ClinicoEcon Outcomes Res. 2011. https://doi.org/10.2147/ ceor.s24130.

4. Eccleston K, Bambumba A, Babu C, et al. Efficacy and safety of tenofovir/ emtricitabine compared to abacavir/lamivudine in HIV-1 infected patients in clinical setting. The TEAL study. J Int AIDS Soc. 2008. https:// doi.org/10.1186/1758-2652-11-s1-p79.

5. Alvarez A, Orden S, Andújar I, et al. Cardiovascular toxicity of abacavir. AIDS. 2017;31(13):1781-95. https://doi.org/10.1097/qad.0000000000 001547

6. Dorjee K, Choden T, Baxi SM, Steinmaus C, Reingold AL. Risk of cardiovascular disease associated with exposure to abacavir among individuals with HIV: a systematic review and meta-analyses of results from 17 epidemiologic studies. Int J Antimicrob Agents. 2018;52(5):541-53. https://doi. org/10.1016/j.ijantimicag.2018.07.010.

7. Molina J, Cahn P, Grinsztejn B, et al. Rilpivirine versus efavirenz with tenofovir and emtricitabine in treatment-naive adults infected with HIV-1 (ECHO): a phase 3 randomised double-blind active-controlled trial. The Lancet. 2011;378(9787):238-46. https://doi.org/10.1016/s0140-6736(11) 60936-7.

8. Cohen C, Andrade-Villanueva J, Clotet B, et al. Rilpivirine versus efavirenz with two background nucleoside or nucleotide reverse transcriptase inhibitors in treatment-naive adults infected with HIV-1 (THRIVE): a phase 3, randomised, non-inferiority trial. The Lancet. 2011;378(9787):229-37. https://doi.org/10.1016/s0140-6736(11)60983-5.

9. Molina J, Clumeck N, Orkin C, et al. Week 96 analysis of rilpivirine or efavirenz in HIV-1-infected patients with baseline viral load $\leq 100000$ copies/mL in the pooled ECHO and THRIVE phase 3 , randomized, doubleblind trials. HIV Med. 2013;15(1):57-62. https://doi.org/10.1111/hiv.12071.

10. Gazaignes S, Resche-Rigon M, Gatey C, et al. Efficacy and safety of a switch to rilpivirine-based regimens in treatment-experienced HIV1-infected patients: a cohort study. Antivir Ther (Lond). 2015;21 (4):329-36. https://doi.org/10.3851/imp3010.

11. Luis Casado J, Bañón S. Recent advances in rilpivirine: new data and promising treatment option. AIDS Rev. 2014;16(3):172-218.

12. Troya J, Ryan P, Ribera E, et al. Abacavir/Lamivudine plus rilpivirine is an effective and safe strategy for HIV-1 suppressed patients: 48 week results of the SIMRIKI retrospective study. PLoS ONE. 2016;11(10): e0164455. https://doi.org/10.1371/journal.pone.0164455.

13. Palacios R, Pérez-Hernández I, Martínez M, et al. Efficacy and safety of switching to abacavir/lamivudine (ABC/3TC) plus rilpivirine (RPV) in virologically suppressed HIV-infected patients on HAART. Eur J Clin Microbiol Infect Dis. 2016;35(5):815-9. https://doi.org/10.1007/ s10096-016-2602-3.

14. Curran A, Rojas J, Cabello A, et al. Effectiveness and safety of an abacavir/ lamivudine + rilpivirine regimen for the treatment of HIV-1 infection in naive patients. J Antimicrob Chemother. 2016;71(12):3510-4. https://doi. org/10.1093/jac/dkw347.

15. Galizzi N, Galli L, Poli A, et al. Long-term efficacy and safety of rilpivirine plus abacavir and lamivudine in HIV-1 infected patients with undetectable viral load. PLoS ONE. 2018. https://doi.org/10.1371/journal.pone. 0191300.

16. Ho S, Wong JG, Ng OT, et al. Efficacy and safety of abacavir/lamivudine plus rilpivirine as a first-line regimen in treatment-naïve HIV-1 infected adults. AIDS Res Ther. 2020;17(1):23. https://doi.org/10.1186/s12981-02000272-5 (PMID: 32438914)

17. Bezabhe WM, Chalmers L, Bereznicki LR, Peterson GM. Adherence to antiretroviral therapy and virologic failure. Medicine. 2016. https://doi. org/10.1097/md.0000000000003361.

18. Karve S, Cleves MA, Helm M, et al. Prospective validation of eight different adherence measures for use with administrative claims data among patients with schizophrenia. Value Health. 2009;12(6):989-95. https://doi. org/10.1111/j.1524-4733.2009.00543.x.

19. Lima VD, Harrigan R, Murray M, et al. Differential impact of adherence on long-term treatment response among naive HIV-infected individuals. AIDS. 2008;22(17):2371-80. https://doi.org/10.1097/qad.0b013e3283 $15 \mathrm{cdd} 3$.

20. Newcombe RG. Two-sided confidence intervals for the single proportion: comparison of seven methods. Stat Med. 1998;17(8):857-72. https://doi. org/10.1002/(sici)1097-0258(19980430)17:8\%3c857::aid-sim777\%3e3.0. co;2-e.

21. Cordova CMMD, Cordova MMD. A new accurate, simple formula for LDLcholesterol estimation based on directly measured blood lipids from a large cohort. Ann Clin Biochem. 2012;50(1):13-9. https://doi.org/10.1258/ acb.2012.011259.

22. KDIGO 2012 Clinical practice guideline for the evaluation and management of chronic kidney disease. https://kdigo.org/wp-content/uploads/ 2017/02/KDIGO_2012_CKD_GL.pdf. Published January 2013.

23. KDIGO Clinical practice guideline for acute kidney injury. https://kdigo. org/wp-content/uploads/2016/10/KDIGO-2012-AKI-Guideline-English. pdf. Published March 2012

24. Giannini EG. Liver enzyme alteration: a guide for clinicians. Can Med Assoc J. 2005:172(3):367-79. https://doi.org/10.1503/cmaj.1040752.

\section{Publisher's Note}

Springer Nature remains neutral with regard to jurisdictional claims in published maps and institutional affiliations.
Ready to submit your research? Choose BMC and benefit from:

- fast, convenient online submission

- thorough peer review by experienced researchers in your field

- rapid publication on acceptance

- support for research data, including large and complex data types

- gold Open Access which fosters wider collaboration and increased citations

- maximum visibility for your research: over 100M website views per year

At $B M C$, research is always in progress.

Learn more biomedcentral.com/submissions 